\title{
Highly processable bulk metallic glass-forming alloys in the $\mathrm{Pt}-\mathrm{Co}-\mathrm{Ni}-\mathrm{Cu}-\mathrm{P}$ system
}

\author{
Jan Schroers ${ }^{a)}$ \\ Keck Laboratory of Engineering Materials, California Institute of Technology, Pasadena, California 91125 \\ and Liquidmetal Technologies, Lake Forest, California 92630 \\ William L. Johnson \\ Keck Laboratory of Engineering Materials, California Institute of Technology, Pasadena, California 91125
}

(Received 10 December 2003; accepted 12 March 2004; published online 20 April 2004)

\begin{abstract}
Highly processable bulk metallic glass alloys in the $\mathrm{Pt}-\mathrm{Co}-\mathrm{Ni}-\mathrm{Cu}-\mathrm{P}$ system were discovered. The alloys show low liquidus temperature below $900 \mathrm{~K}$, excellent processability with low critical cooling rate reflecting in maximum casting thicknesses in quartz tubes of up to $20 \mathrm{~mm}$, and a large supercooled liquid region. The $\mathrm{Pt}_{57.5} \mathrm{Cu}_{14.7} \mathrm{Ni}_{5.3} \mathrm{P}_{22.5}$ composition has a liquidus temperature of 795 $\mathrm{K}$, a glass transition temperature of $508 \mathrm{~K}$ with a supercooled liquid region of $98 \mathrm{~K}$. For medical and jewelry applications a $\mathrm{Ni}$-free alloy, $\mathrm{Pt}_{60} \mathrm{Cu}_{16} \mathrm{Co}_{2} \mathrm{P}_{22}$ was discovered with a liquidus temperature of $881 \mathrm{~K}$, a glass transition temperature of $506 \mathrm{~K}$, and a supercooled liquid region of $63 \mathrm{~K}$. Glass formation was observed in a wider composition range. Vickers hardness of these alloys is in the 400 $\mathrm{Hv}$ range. The alloys can be processed in the supercooled liquid region in air without any measurable oxidation. In this region, a large processing window is available in which the material does not embrittle. Embrittlement in these alloys is correlated with crystallization. It can be avoided as long as substantial crystallization does not take place during isothermal processing in the supercooled liquid region. Also, liquid processing can be performed in air when flux with $\mathrm{B}_{2} \mathrm{O}_{3}$.

(C) 2004 American Institute of Physics. [DOI: 10.1063/1.1738945]
\end{abstract}

Platinum-based alloys are finding more and more applications in fields like jewelry, medical, dental, automotive, microtechnology and nano-technology. They are inert, possess high strength, an esthetic appearance, and a high catalytic potential. Processing of these alloys, however, is very difficult because of their high liquidus temperature in the $2000 \mathrm{~K}$ range. Reaction with the crucible, tarnishing and oxidation, and shrinkage are just some problems resulting from the required high processing temperature.

In the last two decades several alloys based on $\mathrm{Pd},{ }^{1-3}$ $\mathrm{La}^{4}$ and $\mathrm{Zr}^{5,6}$ were discovered which form an amorphous phase during cooling of up to several centimeters at cooling rates of $100 \mathrm{~K} / \mathrm{s}$ or less. These bulk metallic glasses (BMGs) all have in common that their composition is close to a deep eutectic composition. Consequently, their melting temperature is much lower than the linear interpolation of the alloy's constituents liquidus temperatures. The resulting low liquidus temperature is an attractive property for casting alloys. Most uniquely, BMGs show a large temperature difference between glass transition temperature and the crystallization temperature, the so-called supercooled liquid region. In this temperature region the $\mathrm{BMG}$ is in a highly viscous liquid state and can be super plastically deformed, a processing method typically used for plastics.

The best BMG forming alloys were found in the $\mathrm{Pd}-$ $\mathrm{Cu}-\mathrm{Ni}-\mathrm{P}$ system. ${ }^{1-3}$ This system is based on the metalmetalloid $\mathrm{Pd}-\mathrm{P}$ eutectic. Critical casting thicknesses of 72 $\mathrm{mm}^{7}$ and critical cooling rates ${ }^{8}$ of $0.005 \mathrm{~K} / \mathrm{s}$ were measured

\footnotetext{
a) Author to whom correspondence should be addressed; electronic mail: jan.schroers@liquidmetal.com
}

under special fluxing conditions. Due to similar phase diagrams of $\mathrm{Pt}-\mathrm{P}$ and $\mathrm{Pd}-\mathrm{P}$, the $\mathrm{Pt}-\mathrm{P}$ was chosen as the basic system and $\mathrm{Ni}, \mathrm{Cu}$, and $\mathrm{Co}$ were added.

Four different composition regions are studied: An alloy region with maximum processability with a platinum content of at least $85 \%$ by weight; a region with maximum processability with a platinum content of at least $85 \%$ by weight that does not contain any nickel; an alloy that consists of at least $75 \%$ by weight with high processability; and an alloy that consists of at least $75 \%$ by weight with high processability and consists of no more than three elements. Criteria used to

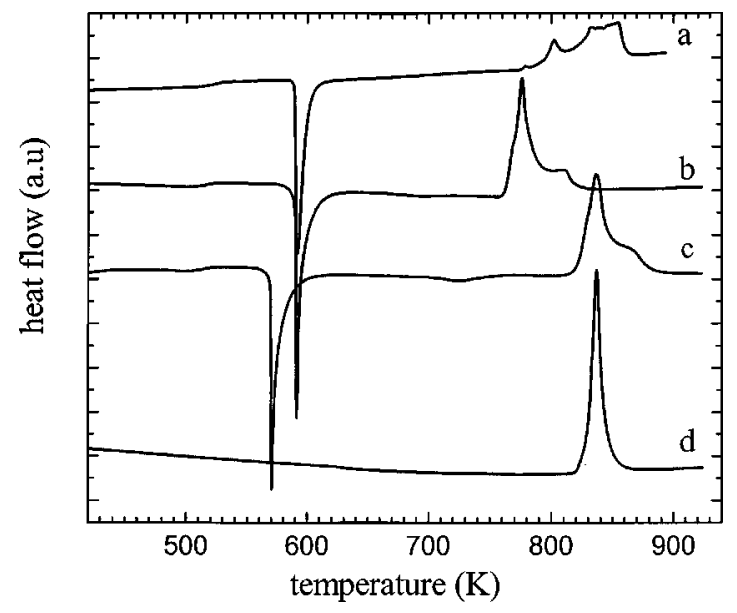

FIG. 1. DSC thermogram determined by heating with $20 \mathrm{~K} / \mathrm{min}$ of Pt-based alloys of various compositions that were cast in various size quartz tubes. (a): $\mathrm{Pt}_{42.5} \mathrm{Cu}_{27} \mathrm{Ni}_{9.5} \mathrm{P}_{21}$ cast in $20 \mathrm{~mm}$ quartz tube, (b): $\mathrm{Pt}_{57.5} \mathrm{Cu}_{14.7} \mathrm{Ni}_{5.3} \mathrm{P}_{22.5}$ cast in $16 \mathrm{~mm}$ quartz tube, (c): $\mathrm{Pt}_{60} \mathrm{Cu}_{16} \mathrm{Co}_{2} \mathrm{P}_{22}$ cast in $12 \mathrm{~mm}$ quartz tube, and (d): $\mathrm{Pt}_{60} \mathrm{Cu}_{20} \mathrm{P}_{20}$ cast in $4 \mathrm{~mm}$ quartz tube. 


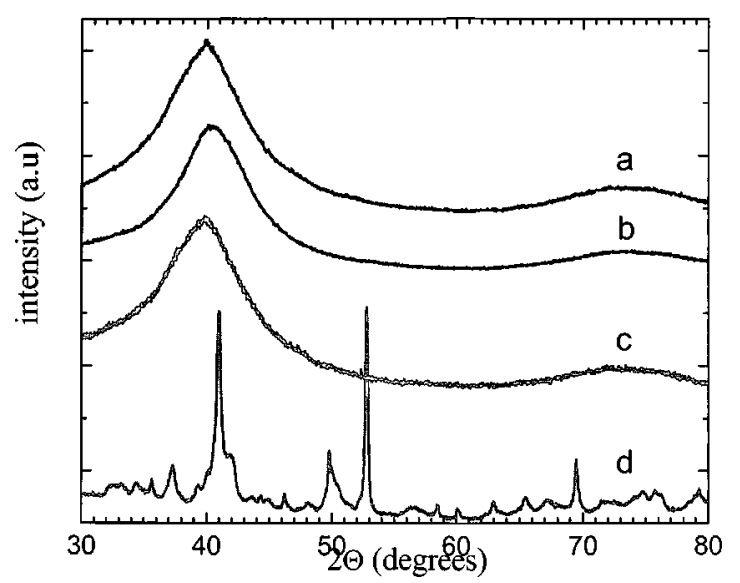

FIG. 2. X-ray diffraction thermogram of Pt-based alloys of various compositions that were cast in various size quartz tubes. (a): $\mathrm{Pt}_{42.5} \mathrm{Cu}_{27} \mathrm{Ni}_{9.5} \mathrm{P}_{21}$ cast in $20 \mathrm{~mm}$ quartz tube, (b): $\mathrm{Pt}_{57.5} \mathrm{Cu}_{14.7} \mathrm{Ni}_{5.3} \mathrm{P}_{22.5}$ cast in $16 \mathrm{~mm}$ quartz tube, (c): $\mathrm{Pt}_{60} \mathrm{Cu}_{16} \mathrm{Co}_{2} \mathrm{P}_{22}$ cast in $12 \mathrm{~mm}$ quartz tube, and (d): $\mathrm{Pt}_{60} \mathrm{Cu}_{20} \mathrm{P}_{20}$ cast in $4 \mathrm{~mm}$ quartz tube.

identify highly processable compositions are large critical casting thickness, large supercooled liquid region, low liquidus temperature, and no embrittlement during thermoplastic processing.

Alloys were prepared by inductively melting the elements (Pt: 99.95, Cu: 99.999, Ni: 99.5, Co: 99.95 P: 99.999 purity) in quartz tubes. Subsequently, the alloy was exposed to a fluxing treatment. $\mathrm{B}_{2} \mathrm{O}_{3}$ was added to the alloy and heated to about $1200 \mathrm{~K}$ for $20 \mathrm{~min}$. This fluxing treatment was found to improve the glass forming ability in various alloys. ${ }^{1,9,10}$ Samples are water quenched in various diameter quartz tubes of a wall thickness of $1 \mathrm{~mm}$.

Thermal analysis is performed in a differential scanning calorimeter (DSC) Netzsch DSC $404 \mathrm{c}$. X-ray diffraction is carried out on an Inel XRG 3000 using $\mathrm{Cu} K \alpha$ radiation. Hardness test was performed on a Leco R-600. Compression tests were carried out on a MTS 810. A large number of compositions were investigated in each abovementioned composition range. From each range only one composition is discussed in detail.

Figure 1 shows the DSC thermogram obtained by heating with $20 \mathrm{~K} / \mathrm{min}$ of the four Pt alloys. The thermogram in Fig. 1(a) is that of $\mathrm{Pt}_{42.5} \mathrm{Cu}_{27} \mathrm{Ni}_{9.5} \mathrm{P}_{21}$ that was cast in a 20 mm quartz tube, Fig. 1(b) shows $\mathrm{Pt}_{57.5} \mathrm{Cu}_{14.7} \mathrm{Ni}_{5.3} \mathrm{P}_{22.5}$ cast in $16 \mathrm{~mm}$, Fig. 1(c) shows $\mathrm{Pt}_{60} \mathrm{Cu}_{16} \mathrm{Co}_{2} \mathrm{P}_{22}$ cast in $12 \mathrm{~mm}$, and Fig. 1(d) shows $\mathrm{Pt}_{60} \mathrm{Cu}_{20} \mathrm{P}_{20}$ that was cast in $4 \mathrm{~mm}$ tube. All compositions are in atomic percent. Except for $\mathrm{Pt}_{60} \mathrm{Cu}_{20} \mathrm{P}_{20}$ all alloys show a glass transition and a crystallization peak suggesting that at least some fraction of the material was amorphous. The liquidus temperature of all alloys is below $900 \mathrm{~K}$.
Figure 2 shows the $\mathrm{x}$-ray diffractogram of the four alloys. The diffractogram in Fig. 2(a) is that of $\mathrm{Pt}_{57.5} \mathrm{Cu}_{14.7} \mathrm{Ni}_{5.3} \mathrm{P}_{22.5}$ that was cast in a $16 \mathrm{~mm}$ quartz tube, Fig. 2(b) shows $\mathrm{Pt}_{60} \mathrm{Cu}_{16} \mathrm{Co}_{2} \mathrm{P}_{22}$ cast in $12 \mathrm{~mm}$, Fig. 2(c) shows $\mathrm{Pt}_{42.5} \mathrm{Cu}_{27} \mathrm{Ni}_{9.5} \mathrm{P}_{21}$ cast in $20 \mathrm{~mm}$, and Fig. 2(d) shows $\mathrm{Pt}_{60} \mathrm{Cu}_{20} \mathrm{P}_{20}$ that was cast in $4 \mathrm{~mm}$ tube. All alloys but the $\mathrm{Pt}_{60} \mathrm{Cu}_{20} \mathrm{P}_{20}$ exhibited broad amorphous peaks with no sharp crystalline peaks. This confirms that all alloys but $\mathrm{Pt}_{60} \mathrm{Cu}_{20} \mathrm{P}_{20}$ are $\mathrm{x}$-ray amorphous.

The results of the various alloys are summarized in Table I. All alloys show very low liquidus temperature compared to commercially crystalline $\mathrm{Pt}$ alloys. $\mathrm{Pt}_{57.5} \mathrm{Cu}_{14.7} \mathrm{Ni}_{5.3} \mathrm{P}_{22.5}$ has a liquidus temperature of $795 \mathrm{~K}$. With a glass transition temperature of $508 \mathrm{~K}$ the reduced glass transition temperature $T_{\mathrm{rg}}=T_{g} / T_{l}=0.64$, a value only seen among extraordinarily good glass formers. The supercooled liquid region for $\mathrm{Pt}_{60} \mathrm{Cu}_{16} \mathrm{Co}_{2} \mathrm{P}_{22}$ and $\mathrm{Pt}_{42.5} \mathrm{Cu}_{27} \mathrm{Ni}_{9.5} \mathrm{P}_{21}$ is larger than $60 \mathrm{~K}$ and for $\mathrm{Pt}_{57.5} \mathrm{Cu}_{14.7} \mathrm{Ni}_{5.3} \mathrm{P}_{22.5}$ it reaches $98 \mathrm{~K}$. A large supercooled liquid region is crucial for thermo plastic processing. Also shown in Table $\mathrm{I}$ are the hardness numbers. For $\mathrm{Pt}_{57.5} \mathrm{Cu}_{14.7} \mathrm{Ni}_{5.3} \mathrm{P}_{22.5}, \mathrm{Pt}_{60} \mathrm{Cu}_{16} \mathrm{Co}_{2} \mathrm{P}_{22}$, and $\mathrm{Pt}_{42.5} \mathrm{Cu}_{27} \mathrm{Ni}_{9.5} \mathrm{P}_{21}$ the Vickers hardness number is around $V_{H}=400$. This is about twice as hard as conventional crystalline Pt alloys typically used for jewelry applications. The maximum casting thicknesses are also shown in Table I. Large maximum casting thicknesses of up to $20 \mathrm{~mm}$ for the $\mathrm{Pt}_{42.5} \mathrm{Cu}_{27} \mathrm{Ni}_{9.5} \mathrm{P}_{21}$ were measured reflecting the good glass forming ability.

It should be mentioned that a larger composition range for all four alloys was studied. As an example in the range of the $\mathrm{Pt}_{57.5} \mathrm{Cu}_{14.7} \mathrm{Ni}_{5.3} \mathrm{P}_{22.5}$ alloy platinum was increased up to $63 \%$, Ni was varied from $0 \%$ to $10 \%, \mathrm{Cu}$ from $6 \%$ to $16 \%$, and $\mathrm{P}$ from $18 \%$ to $25 \%$. Among the constituents of the alloy, the $\mathrm{P}$ content has the strongest influence on the glass forming ability. For example $\mathrm{Pt}_{60} \mathrm{Cu}_{14.7} \mathrm{Ni}_{5.3} \mathrm{P}_{20}$ could not be cast amorphous in $10 \mathrm{~mm}$ tubes or larger, whereas $\mathrm{Ni}, \mathrm{Cu}$, and $\mathrm{P}$ could be varied in the abovementioned range and still be cast amorphous at least into $12 \mathrm{~mm}$ tubes.

In a recent publication Zhang and Inoue ${ }^{11}$ observed a critical casting thickness for $\mathrm{Pt}_{60} \mathrm{Cu}_{20} \mathrm{P}_{20}$ of at least $12 \mathrm{~mm}$ when casting in copper molds. In the present publication even in $4 \mathrm{~mm}$ quartz tubes the $\mathrm{Pt}_{60} \mathrm{Cu}_{20} \mathrm{P}_{20}$ alloy could not be solidified amorphous. This discrepancy in the thicknesses the material can be cast amorphous in, can be explained by the different casting techniques used. Even for perfect wetting the low thermal conductivity of about $1.3 \mathrm{~W} / \mathrm{m} \mathrm{K}$ for quartz compared to about $10 \mathrm{~W} / \mathrm{m} \mathrm{K}$, a typical value for BMGs, makes the quartz a thermal barrier for the cooling process. The heat flow kinetics through a $4 \mathrm{~mm} \mathrm{Pt}_{57.5} \mathrm{Cu}_{14.7} \mathrm{Ni}_{5.3} \mathrm{P}_{22.5}$ sample in a quartz tube of $1 \mathrm{~mm}$ wall thickness is comparable to the heat flow through a $\mathrm{Pt}_{57.5} \mathrm{Cu}_{14.7} \mathrm{Ni}_{5.3} \mathrm{P}_{22.5}$ sample

TABLE I. Summary of the properties of the various Pt-based alloys. The maximum thickness the alloy could be cast amorphous, $d_{\max }$, was determined for water quenching in quartz tubes of $1 \mathrm{~mm}$ wall thickness.

\begin{tabular}{lccccccc}
\hline \hline Composition [at. \%] & $\begin{array}{c}T_{g} \\
(\mathrm{~K})\end{array}$ & $\begin{array}{c}T_{X} \\
(\mathrm{~K})\end{array}$ & $\begin{array}{c}\Delta T \\
(\mathrm{~K})\end{array}$ & $\begin{array}{c}T_{1} \\
(\mathrm{C})\end{array}$ & $\begin{array}{c}T_{\mathrm{rg}} \\
=T_{1} / T_{g}\end{array}$ & $\begin{array}{c}d_{\text {max }} \text { quartz } \\
\text { tube }(\mathrm{mm})\end{array}$ & Hardness, $R_{a}$ \\
\hline $\mathrm{Pt}_{57.5} \mathrm{Cu}_{14.7} \mathrm{Ni}_{5.3} \mathrm{P}_{22.5}$ & 508 & 606 & 98 & 795 & 0.64 & 16 & 402 \\
$\mathrm{Pt}_{42.5} \mathrm{Cu}_{27} \mathrm{Ni}_{9.5} \mathrm{P}_{21}$ & 515 & 589 & 74 & 873 & 0.59 & 20 & 392 \\
$\mathrm{Pt}_{60} \mathrm{Cu}_{16} \mathrm{Co}_{2} \mathrm{P}_{22}$ & 506 & 569 & 63 & 881 & 0.58 & 16 & 402 \\
$\mathrm{Pt}_{60} \mathrm{Cu}_{20} \mathrm{P}_{20}$ & & & & 844 & & $<4$ & \\
\hline \hline
\end{tabular}




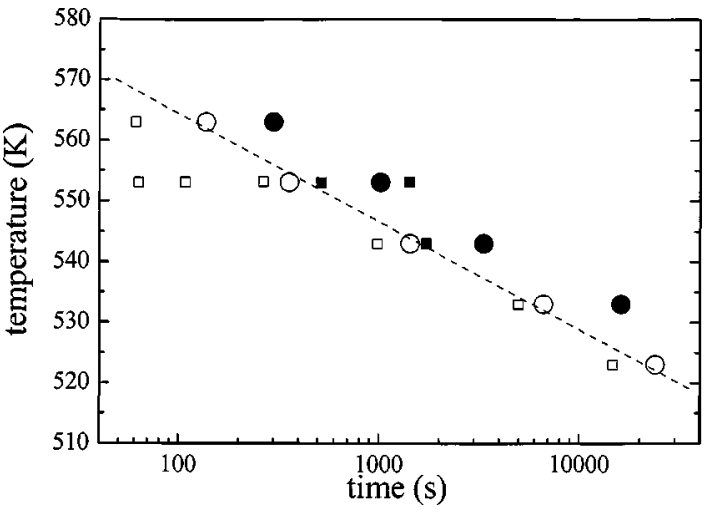

FIG. 3. Time-temperature-transformation diagram for amorphous $\mathrm{Pt}_{57.5} \mathrm{Cu}_{14.7} \mathrm{Ni}_{5.3} \mathrm{P}_{22.5}$ heated into the supercooled liquid region. Open circles depict onset of crystallization and closed circles the end of the crystallization. Squares indicate annealing conditions for failure mode determination. The open squares indicate a ductile behavior and the closed squares a brittle failure. The dashed line guides the eye to distinguish the region from ductile to brittle failure.

of about $18 \mathrm{~mm}$. Therefore, critical casting thicknesses should only be compared with each other when the same quenching technique is used.

In order to explore the superplastic processability the time available before crystallization sets in was determined. Therefore, amorphous material was heated in the supercooled liquid region and processed isothermally until crystallization sets in. The onset of crystallization was determined by a heat release due to the release of the heat of fusion during crystallization. The isothermal studies on $\mathrm{Pt}_{57.5} \mathrm{Cu}_{14.7} \mathrm{Ni}_{5.3} \mathrm{P}_{22.5}$ result in a time temperature transformation (TTT) diagram which is shown in Fig. 3. A common phenomenon when BMGs are reheated into the supercooled liquid region is the embrittlement, a drastic decrease in the fracture toughness ${ }^{12}$ which makes the material useless for most applications. An effective way to qualitatively estimate the embrittlement is a hardness test. It should be mentioned that this method allows one to determine a change in the fracture mode but is not capable of determining the absolute fracture toughness. The studied alloys show in the as-cast state a Vickers hardness around $400 \mathrm{Hv} . \mathrm{Pt}_{57.5} \mathrm{Cu}_{14.7} \mathrm{Ni}_{5.3} \mathrm{P}_{22.5}$ was annealed at different temperatures and times before and after the onset of crystallization as indicated by squares in Fig. 3. The embrittlement is evidenced by snapping of the disk shape sample during loading in the hardness test. Samples that snapped during loading are considered to be brittle and they are shown as solid squares. Samples that did not snap during loading were considered to be ductile and are shown as open squares. The hardness number measured on the material that did not snap remain unchanged within experimental scatter. For this alloy the embrittlement is correlated with the crystallization. This is in contrast to Zr-based alloys where embrittlement was observed prior to crystallization. ${ }^{12}$ In order to further investigate the influence of annealing in the supercooled liquid region, the effect of the isothermal processing on the compressive yield strength was investigated. Therefore, a $\mathrm{Pt}_{57.5} \mathrm{Cu}_{14.7} \mathrm{Ni}_{5.3} \mathrm{P}_{22.5}$ sample that was subject to heat treatment of $180 \mathrm{~s}$ at $643 \mathrm{~K}$ and as-cast material was compared. Both samples show a yield strength of about 1.1 GPa.

The alloys' resistivity to oxidation was determined by processing both in air and in an argon atmosphere at $533 \mathrm{~K}$ for $30 \mathrm{~min}$. Since with the naked eye no difference could be determined, x-ray photoemission spectroscopy (XPS) was utilized to determine oxidation. It turns out that between the differently processed samples no difference in the XPS spectrum could be revealed.

In conclusion, Pt-based alloys were developed that consist of at least $75 \%$ by weight of platinum, $\mathrm{Pt}_{42.5} \mathrm{Cu}_{27} \mathrm{Ni}_{9.5} \mathrm{P}_{21}$, an alloy that consists of at least $85 \%$ by weight of platinum, $\mathrm{Pt}_{57.5} \mathrm{Cu}_{14.7} \mathrm{Ni}_{5.3} \mathrm{P}_{22.5}$ of platinum and an alloy that consists of at least $85 \%$ by weight but does not consist of $\mathrm{Ni}, \mathrm{Pt}_{60} \mathrm{Cu}_{16} \mathrm{Co}_{2} \mathrm{P}_{22}$. These alloys show low liquids temperature, large supercooled liquid region, large maximum casting thickness, and good processability both for casting and for thermoplastic processing. The fact that the alloys do not embrittle during isothermal processing prior to crystallization, and their large supercooled liquid region make them promising candidates for thermoplastic processing.

${ }^{1}$ H. W. Kui, A. L. Greer, and D. Turnbull, Appl. Phys. Lett. 45, 615 (1984).

${ }^{2}$ N. Nishiyama and A. Inoue, Mater. Trans., JIM 37, 1531 (1996).

${ }^{3}$ I.-R. Lu, G. Wilde, G. P. Görler, and R. Willnecker, J. Non-Cryst. Solids 250-252, 577 (1999).

${ }^{4}$ A. Inoue, H. Yamaguchi, T. Zhang, and T. Masumoto, Mater. Trans., JIM 31, 104 (1990).

${ }^{5}$ A. Inoue, T. Zhang, and T. Masumoto, Mater. Trans., JIM 31, 177 (1990).

${ }^{6}$ A. Peker and W. L. Johnson, Appl. Phys. Lett. 63, 2342 (1993).

${ }^{7}$ A. Inoue, N. Nishiyama, and H. Kimura, Mater. Trans., JIM 38, 179 (1997).

${ }^{8}$ J. Schroers and W. L. Johnson, Appl. Phys. Lett. 80, 2069 (2002).

${ }^{9}$ T. D. Shen and R. B. Schwarz, Appl. Phys. Lett. 75, 49 (1999).

${ }^{10}$ J. Schroers, Y. Wu, and W. L. Johnson, Philos. Mag. A 82, 1207 (2002).

${ }^{11}$ T. Zhang and A. Inoue, Mater. Trans., JIM 44, 1143 (2003).

${ }^{12}$ C. G. Gilbert, R. O. Ritchie, and W. L. Johnson, Appl. Phys. Lett. 71, 476 (1997). 